\title{
Evaluating the Effect of Solution-Focused Group Counseling on Improving Quality of Marital Relationships in Childless Couples
}

\author{
Khadijeh Panahi Dorche ${ }^{1}$, Seyed Ali Kimiaei ${ }^{2} \&$ Melika Ghahramanzadeh $^{2}$ \\ ${ }^{1}$ Islamic Azad University of Khorasan Razavi, Nishapur Unit, Iran \\ ${ }^{2}$ Ferdowsi University of Mashhad, Mashhad, Iran \\ Correspondence: Seyed Ali Kimiaei, Azadi Square, Ferdowsi University of Mashhad, Mashhad, Khorasan \\ Razavi, Iran. Tel: 98-915-500-8538. E-mail: kimiaee@um.ac.ir
}

Received: December 5, 2015

Accepted: December 5, 2016 Online Published: January 9, 2017

doi:10.5539/ijps.v9n1p81

URL: http://dx.doi.org/10.5539/ijps.v9n1p81

\begin{abstract}
This study investigated the effect of solution-focused counseling on improving the quality of marital relationships on childless couples. This study is a quasi-experimental using pre-test, post-test with a waiting list control group. Sample population of this study was visiting in a Welfare and Education center in city of Eafahan. Fourteen couples were selected randomly through stratified random sampling method and were equally assigned to experimental and waiting list control groups. They completed the Dyadic Adjustment Scale (DAS). The results showed that solution-focused counseling not only significantly increases the quality of marital relationship but also improve dyadic consensus, affective expression, dyadic cohesion and marital satisfaction.
\end{abstract}

Keywords: solution-focused counseling, quality of marital relationship, childless couples

\section{Introduction}

The quality of marital relationships is a multi-dimensional concept including various aspects of couples relationships such as compatibility, satisfaction, happiness, cohesion and commitment (Eisanejad, Ahmadi, \& E'temadi, 2009, p. 10). Marital satisfaction is an important condition in marriage in which the spouses most of the time feel happy and content with each other and their marriage (Poorchelo, 2011, p. 3).

Beck and Jones (1972) quoted in (Sapington, 2001), realized that the most common problem in challenging and troublesome marriages is poor quality of marital relationships (Yousofi, Bashlideh, Eisanejad, E'temadi, \& Shirbegi, 2011).

Regarding the influence of children on marital satisfaction, Lucky and Bain (1989) believe that marital satisfaction follows a descending trend after the birth of children and women feel the dissatisfaction more strongly than men. The arrival of children creates expectations which can further broaden the gap between the spouses (Olia Fatehizadeh \& Bahrami, 2011, p. 22).

Various methods have been used to improve the quality of marital relationships between couples and some studies have been conducted in this field. The present study uses the solution-focused short-term approach which is one of the postmodernism therapeutic approaches. The founders of solution-focused treatment, Steve Dyshazr and Inso Berg et al. work in the US short-term family therapy center which began its activity in 1979 (Nichols, Michael, Schwartz, \& Richard, 2010, p. 601). The experts at this center were very excited to report the successful results and high satisfaction of the clients in using the solution-focused approach.

According to Stewart (2011), the short-term solution-focused approach was used to improve couples' satisfaction with their relationships, skills, and individual performance, and the results showed that the couples felt satisfied after participating in this couple therapy program. Javanmiri, Kimiaei and Ghanbri Hashemabadi (2012) conducted a study and concluded that solution-focused group counseling reduces depression.

In their studies, Nazari (2004), Nazari and Bahrami (2008), Attari, Mohammadi, and Mehrabizadeh (2009), Qamari (2009) Vahid Vaqef, Shafi'abadi, and Mo'een (2010), Soudani, Shafi'abadi, and E'temadi (2010), and Kimiaei, Salehi Fadredi, and Azadi (2011) concluded that the solution-focused therapy approach improves couples' satisfaction and adjustment. A review of the studies conducted on the short-term solution-focused 
approach between 1982 and 2000 shows that this approach has had a strong effect in most of those studies. This approach can create considerable progress in social work and the special counseling viewpoint (Davoodi, 2012).

Due to the significance of the relationships between spouses, and because the quality of this relationships directs their married life, this paper attempts to investigate the significant variable of the marital relationships between spouses which is the quality of marital relationships. Hence, the present study attempts to answer the questions as to whether couples' counseling together with the short-term solution-focused approach can help improve couples' marital relationships, or we should find other methods to improve couples' skills in tackling their family and marital problems.

\section{Method}

This study tested 5 hypotheses. The main hypothesis is: solution-focused counseling has a positive impact on the quality of couple's marital relationship. The secondary hypotheses are: 1) Solution-focused counseling has a positive effect on couples' marital dyadic consensus; 2) Solution-focused counseling has a positive effect on couples' dyadic affection expression; 3) Solution-focused counseling has a positive effect on couples' dyadic cohesion; and 4) Solution-focused counseling has a positive effect on couples' marital satisfaction.

The population comprised childless couples in the first five years of marriage living in the city of Isfahan, Iran. The sample was randomly selected among the population of those who had the features desired in research. The participants were ultimately selected after the final interview and the research objective was fully explained to the couples. The couples randomly selected were divided into two experimental (7 couples) and waiting list control groups ( 7 couples).

This study was a quasi-experimental piece of research following a pretest-posttest design including two experiment and waiting list control groups conducted in the spring of 2014 in the city of Isfahan. Some factors such as being intelligent (lack of mental retardation), age, education, lack of mental disorders, lack of child, being in first five years of marriage, living together, free of any important individual psychopathology, free of drug or alcohols problems, not in intense marital crisis (no pending divorce or physical abuse) and not currently following another therapy was identified and almost equalized. After the pre-test was administered in both waiting list control and experimental groups, the independent variable (short-term solution-focused counseling) was applied in the experimental group. The control group, however, did not received any intervention and remained on the waiting list.

During the assessment interview, all couples completed Dyadic Adjustment Scale (DAS) Graham and Spanier (1976). This scale is aimed at evaluating the quality of marital relationship or similar dyadic relationships. It measures four dimensions: 1) dyadic satisfaction, 2) dyadic cohesion, 3) dyadic consensus, and 4) dyadic affection expression. The scoring method of this scale yielded three different ranking scales. The total score of the sum of all the questions was between 0 and 151. Higher scores indicate better relationship. Questions of the subscales are as follows: marital satisfaction: 16, 17, 18, 19, 20, 21, 22, 23, 31; dyadic cohesion: 25, 25, 26, 27, 28, 32; consensus: 1, 2, 3, 5, 8, 9, 10,11,12,13, 14, 15; and affection expression: 4, 6, 29, 30 .

The marital adjustment scale consisted of a sample group including married $(\mathrm{N}=218)$ and divorced $(\mathrm{N}=94)$ individuals. For the married individuals, the total mean score of dyadic adjustment scale was 114.8 and the standard deviation was 17.8. For the divorced, the mean was 70.7 and the standard deviation was 8.32 . The validity of the scale was verified using logical content analysis methods, and the scale was found to have concurrent validity too. It also has a correlation with Lock-Wallace's marital satisfaction scale. Validity: The total score of the scale with a Cronbach's alpha of $96 \%$ has considerable internal consistency. The internal consistency of the subscales varies from good to excellent. Dyadic satisfaction $=0.96$, dyadic cohesion $=0.81$, dyadic consensus $=0.90$, affection expression $=0.73$. In the study conducted by Mullazadeh, Mansouri, Eje'I and Kianmanesh (2008), the internal consistency of this instrument was 0.95\% (Sanayee, 2008, pp. 38-39).

To conduct the study, after determining the research objectives, defining the population, selecting and assigning the sample (the couples) into two groups randomly, and implementation of the relationship quality scale as the pretest, 14 couples ultimately participated in the study. After explaining and clarifying the procedure for the two groups, the experimental group was asked not to use any other counseling classes or workshop during while receiving counseling and to regularly participate in solution-focused counseling sessions. The control group also was asked not to use any other counseling classes or workshop during this time and to refer at the determined time so that the aforementioned questionnaire is re-administered to them as post-est.

For the experiment group (for each couple), counseling sessions with a solution-focused approach as the independent variable and the interventional method were held once a week for 60 to 75 minutes in accordance 
with the needs of the couples. At the end of the sessions, the above-mentioned questionnaire was re-administered to both groups as post-test, and, afterwards, the data resulting from pre-test and post-test were analyzed using statistical methods in accordance with research objectives. Descriptive and inferential statistics were used to analyze the data and test the hypotheses. The data was summarized using descriptive statistic indices, i.e., mean, standard deviation, and standard error. In the inferential statistics section, analysis of covariance, variance, and MANCOVA analysis tests were used by SPSS software.

\section{Results}

The results obtained from inferential statistics including analysis of variance and covariance analysis and MANCOVA tests are presented in Table 1.

Table 1. Results of Shapiro-Wilk and Levene's test regarding the presupposition of normality of scores distribution and equality of variances

\begin{tabular}{|c|c|c|c|c|c|c|c|c|}
\hline \multirow[b]{2}{*}{$\begin{array}{l}\text { Normal distribution } \\
\text { of scores }\end{array}$} & \multirow[b]{2}{*}{ Groups } & \multicolumn{3}{|c|}{ Shapiro-Wilk } & \multicolumn{4}{|c|}{ Levene } \\
\hline & & Statistic & $\begin{array}{l}\text { Degree of } \\
\text { freedom }\end{array}$ & significance & $\mathrm{F}$ & $\begin{array}{l}\text { First degree of } \\
\text { freedom } \\
\text { (numerator) }\end{array}$ & $\begin{array}{l}\text { Second degree } \\
\text { of freedom } \\
\text { (denominator) }\end{array}$ & Significance \\
\hline \multirow{2}{*}{$\begin{array}{l}\text { Quality of } \\
\text { relationship (Total) }\end{array}$} & Experimental & $0 / 117$ & 14 & $0 / 200$ & $0 / 631$ & 1 & 26 & $0 / 434$ \\
\hline & Control & $0 / 124$ & 14 & $0 / 200$ & & & & \\
\hline
\end{tabular}

As presented in Table 1, the null hypothesis regarding the normal distribution of the scores in two groups is confirmed. Also, the null hypothesis for the equality of variance of the two groups scores in research main hypothesis is confirmed in the post-test.

Table 2. Results of Shapiro-Wilk and Levene tests regarding the presupposition on the normality of distribution of scores and equality of variances

\begin{tabular}{|c|c|c|c|c|c|c|c|c|}
\hline \multirow{2}{*}{$\begin{array}{l}\text { Normal } \\
\text { distribution } \\
\text { of scores }\end{array}$} & \multirow[b]{2}{*}{ Groups } & \multicolumn{3}{|c|}{ Shapiro-Wilk } & \multicolumn{4}{|c|}{ Levene } \\
\hline & & Statistic & $\begin{array}{l}\text { Degree of } \\
\text { freedom }\end{array}$ & Significance & $\mathrm{F}$ & $\begin{array}{l}\text { First degree of } \\
\text { freedom (numerator) }\end{array}$ & $\begin{array}{l}\text { Second degree of freedom } \\
\text { (denominator) }\end{array}$ & Significance \\
\hline \multirow{2}{*}{$\begin{array}{l}\text { Dyadic } \\
\text { consensus }\end{array}$} & Experimental & $0 / 303$ & 14 & $* 0 / 001$ & $0 / 149$ & 1 & 26 & $0 / 702$ \\
\hline & Control & $0 / 168$ & 14 & $0 / 200$ & & & & \\
\hline \multirow{2}{*}{$\begin{array}{l}\text { Affection } \\
\text { expression }\end{array}$} & Experimental & $0 / 179$ & 14 & $0 / 200$ & $0 / 932$ & 1 & 26 & $0 / 343$ \\
\hline & Control & $0 / 249$ & 14 & $* 0 / 018$ & & & & \\
\hline \multirow{2}{*}{$\begin{array}{l}\text { Dyadic } \\
\text { cohesion }\end{array}$} & Experimental & $0 / 297$ & 14 & $* 0 / 002$ & $1 / 239$ & 1 & 26 & $0 / 276$ \\
\hline & Control & $0 / 190$ & 14 & $0 / 185$ & & & & \\
\hline \multirow{2}{*}{$\begin{array}{l}\text { Marital } \\
\text { satisfaction }\end{array}$} & Experimental & $0 / 164$ & 14 & $0 / 200$ & $2 / 880$ & 1 & 26 & $0 / 102$ \\
\hline & Control & $0 / 131$ & 14 & $0 / 200$ & & & & \\
\hline
\end{tabular}

As presented in Table 2, the null hypothesis regarding the normal distribution of the scores in two groups are confirmed in most variables. Besides, the null hypothesis for the equality of variances of two group scores in research main hypothesis is confirmed in the post-test. 
Table 3. Results of analysis of covariance on the effect of group membership on the couples' relationship quality scores

\begin{tabular}{lllllllll}
\hline Variable & Sum squares & $\begin{array}{l}\text { of } \\
\text { freedom }\end{array}$ & $\begin{array}{l}\text { level } \\
\text { squares }\end{array}$ & $\begin{array}{l}\text { of mean } \\
\text { s }\end{array}$ & $\begin{array}{l}\text { significance } \\
\text { effect }\end{array}$ & $\begin{array}{l}\text { degree } \\
\text { of }\end{array}$ & Statistical power \\
\hline Pretest 1 & 777.891 & 1 & & $777 / 891$ & $33 / 388$ & $* * 0 / 001$ & $0 / 572$ & 1 \\
Group membership & $4979 / 924$ & 1 & $4979 / 924$ & $213 / 743$ & $* * 0 / 001$ & $0 / 895$ & 1 & \\
Error & $582 / 466$ & 25 & $23 / 299$ & & & & & \\
\hline
\end{tabular}

The results presented in Table 3 demonstrate that after eliminating the effect of synchronous variables on the dependent variable and considering the calculated $\mathrm{F}$, it is observed that there is a significant difference between the modified mean scores of the quality of couples' relationship in terms of group membership in the post-test stage $(\mathrm{P}<0.001)$. Hence, the main hypothesis was confirmed. Therefore, solution-focused counseling has helped to enhance the scores of relationship quality between the couples who had participated in the study. The degree of this effect was found to be $0 / 895$ in the post-test stage.

Therefore, there were differences between the post-test mean scores of dyadic consensus, affection expression, dyadic cohesion and marital satisfaction of the control and experiment groups.

Table 4. Results of MANCOVA analysis on the mean scores of the relationship quality components

\begin{tabular}{llllllll}
\hline Test name & Value & F & DF & DF & Significance (P) & Eta square & Statistical power \\
& & & Hypothesis & Error & & \\
\hline Wilks's lambda test & $0 / 075$ & $58 / 612$ & $4 / 000$ & $19 / 000$ & $* * 0 / 001$ & $0 / 925$ & 1 \\
\hline
\end{tabular}

As presented in Table 4, the significance levels of the test indicate that in the post-test stage, at least in one of the components of dyadic consensus, affection expression, dyadic cohesion, and marital satisfaction in relation to the two control and experimental groups, the mean score of the experimental group has been increased compared to the control group.

Table 5. Results of MANCOVA analysis related to the effect of group membership on the scores of the relationship quality components

\begin{tabular}{|c|c|c|c|c|c|c|c|c|}
\hline Variable & & $\begin{array}{l}\text { Sum } \\
\text { squares }\end{array}$ & $\begin{array}{l}\text { of degree } \\
\text { freedom }\end{array}$ & $\begin{array}{l}\text { of mean } \\
\text { squares }\end{array}$ & $\mathrm{F}$ & significance & $\begin{array}{l}\text { degree of } \\
\text { effect }\end{array}$ & $\begin{array}{l}\text { detected } \\
\text { power }\end{array}$ \\
\hline \multirow[t]{2}{*}{$\begin{array}{l}\text { Dyadic } \\
\text { consensus }\end{array}$} & $\begin{array}{l}\text { Group } \\
\text { membership }\end{array}$ & 672.897 & 1 & 672.897 & $79 / 868$ & $* * 0.001$ & 0.784 & 1 \\
\hline & Error & 185.352 & 22 & 8.425 & & & & \\
\hline \multirow[t]{2}{*}{$\begin{array}{l}\text { Affective } \\
\text { expression }\end{array}$} & $\begin{array}{l}\text { Group } \\
\text { membership }\end{array}$ & 21.736 & 1 & 21.736 & $35 / 337$ & $* * 0.001$ & 0.616 & 1 \\
\hline & Error & 13.532 & 22 & 0.615 & & & & \\
\hline \multirow[t]{2}{*}{ Dyadic cohesion } & $\begin{array}{l}\text { Group } \\
\text { membership }\end{array}$ & $95 / 666$ & 1 & $95 / 666$ & $21 / 041$ & $* * 0.001$ & 0.489 & 0.992 \\
\hline & Error & 100.026 & 22 & 4.547 & & & & \\
\hline \multirow[t]{2}{*}{$\begin{array}{l}\text { Marital } \\
\text { satisfaction }\end{array}$} & $\begin{array}{l}\text { Group } \\
\text { membership }\end{array}$ & $453 / 560$ & 1 & $453 / 560$ & $126 / 092$ & $* * 0.001$ & 0.851 & 1 \\
\hline & Error & 79.135 & 22 & 3.579 & & & & \\
\hline
\end{tabular}




\section{Discussion}

The statistical method of covariance analysis was used to analyze the results of this study. The pre-test variable was controlled in all the hypotheses, and all of the hypotheses were confirmed. Considering the coefficient of effect, it can be concluded that short-term solution-focused counseling was influential and increased the quality of couples' marital relationship.

The main hypothesis: Solution-focused counseling has a significant positive impact on the quality of relationship of the couples in the experimental groups as compared to those of the control group. There is a significant difference between the modified mean scores of the quality of couples' relationship in terms of group membership (control and experimental group) in the post-test stage. Therefore, the first hypothesis is confirmed. So, solution-focused counseling had effects on increasing the quality scores of couples relationship participating in the experimental group in the post-test. The amount of effect was $0 / 895$ in the post-test. This difference existed in the pre-test stage too which its effect was controlled using covariance analysis.

There is a significant difference between post-test mean scores of marital satisfaction, dyadic consensus, and dyadic cohesion of the control and experiment groups. In general, the mean scores of quality of couples relationship in the experimental group are significantly higher than that of the control group. Nazari and Berami (2008) conducted a study to investigate the effect of solution-focused counseling on marital satisfaction in terms of aggression, the time spent with each other, agreement on financial issues, and sexual satisfaction in couples. The results showed that solution-focused counseling significantly increased the above-mentioned variables (Nazari \& Beirami, 2008). Hence, those results are consistent with the results of the present study.

Hypothesis 1: Solution-focused counseling has a significant positive effect on dyadic consensus of the experiment group couples in comparison with the control group $(\mathrm{P}<0.001)$. Therefore, the first hypothesis is confirmed. Given the computed $\mathrm{F}$, there is a significant difference in the post-test stage. This impact is $0 / 784$ in the posttest stage.

Ahmadi (2003) in a study concluded that dyadic relationship (between couples) and understanding in interpersonal relationships have the highest power of prediction in compatibility. Among these factors, dyadic (couples') relationship was found to be the pivotal factor of marital adjustment (Olia et al., 2011, p. 10). Having conducted a long-term study, Aaron, Thurman and Aaron (2001), as quoted in Harvey, concluded that when couples come to mutual agreement on hopeful activities for a while, the quality of their marriage will be enhanced (Harveey, 2009, p. 599). These findings are consistent with the findings of the present study regarding the fact that couples' dyadic consensus enhances their marriage quality.

Hypothesis 2: Solution-focused counseling has a significant positive effect on affection expression of the couples in the experimental group in comparison to the control group. Considering the computed $\mathrm{F}$, it was observed that in the post-test stage, there was a significant difference between the modified mean scores of affection expression. Hence, the second hypothesis is confirmed. Therefore, solution-focused counseling had a significant effect on the increase in the scores of affection expression of the couples in the experimental group in the post-test stage. The degree of this effect was found to be 0/616 in the post-test. Sehat, Sehat and Khanjani (2013) conducted a study to investigate the effect of solution-focused approach on the increase in adjustment. They concluded that solution-based training has had a significant effect on marital adjustment and the dimensions of satisfaction, cohesion and affection expression. Those findings are consistent with the findings of the present study regarding the effect of solution-focused counseling on couples' affection expression.

Hypothesis 3: Considering the calculated F coefficient, it was observed that in the post-test stage, there was a significant difference between the modified mean scores and scores of dyadic cohesion. Therefore, hypothesis 3 is confirmed. Hence, solution-focused counseling has a significant effect on the increase in the score of dyadic cohesion of the couples in the posttest stage. The degree of this effect in the post-test stage was determined to be $0 / 489$.

Hypothesis 4: Solution-focused counseling has a significant positive effect on the marital satisfaction of the couples in the experiment group in comparison to the control group. Considering the F coefficient calculated, it was observed that in the post-test stage there is a significant difference between the modified scores of marital satisfaction of the participating couples. Therefore, hypothesis 4 is confirmed. Hence, solution-focused counseling has an effect on the increase in the marital satisfaction of the participating couples in the post-test stage. The degree of this effect in the post-test stage was found to be $0 / 851$.

According to the statistical results of MANCOVA, among components of quality of couples' marital relationship, solution-focused counseling had the highest effect on the marital satisfaction (hypothesis 4 ) with a score of 0/851 and the lowest effect on couples' dyadic cohesion (hypothesis 3 ) with a score of $0 / 489$. 
Zimmerman, Prest and Wetzel (1997), as quoted in Nazari et al. (2004) investigated the efficacy of solution-focused group couple therapy in improving and increasing marital satisfaction. The findings showed that the experimental group had been significantly improved in comparison to the control group in the subscales of marital like-mindedness, marital satisfaction, affective expression, and marital cohesion. This confirms the effectiveness of the solution-focused approach in improving marital satisfaction (2004, p. 6). Vahid Vaghef et al. (2010) and Nazari (2004) conducted studies to investigate the effectiveness of solution-focused counseling. They found that using this approach in counseling increases couples' marital satisfaction. The results of those studies are consistent with the results of the present study regarding the effect of solution-focused counseling on the quality of couples' marital relationship.

\section{Conclusion}

According to the previous research on solution-focused counseling and the results of the present study, it can be argued that solution-focused counseling can be used as a short term therapeutic approach to help improve the quality of couples' marital relationship and an appropriate solution to their problems. Given the individual, sexual and educational differences and the findings of the present study, the degree of effect of the solution-focused approach on couples varies between couples. This should be brought to the attention of therapists and counselors who apply this approach. In the present study, the couples learned to find the proper solution of the problems on their own. Considering the cooperation and the emphasis on the process, minor changes can lead to major ones.

Some considerable differences were found between men's and women's attitude to life quality, because men and women adopt different roles and have different views of various aspects of relationships (such as division of tasks, parenting and sexual population) (Khajeh, Bahrami, Fatehi, Abedi, \& Sajadian, 2013, p. 66). Some investigations have reported that marriage satisfaction is lower in women than in men (Rajabi, 2009). Mudd (2000) found that men and women have different ways of responding to the solution-focused method. The present study, also indicates that there are differences between men's and women's views toward the variables of marital relationship quality based on the findings obtained from statistical analyses. According to the findings of the above-mentioned studies as well as the results of the present study and the effectiveness of the solution-focused method on couples' relationships quality variables, this approach can be used as a therapeutic and preventive method.

\section{References}

Attari, Y. A., Mohammadi, K., \& Mehrabizadeh, M. (2009). Investigating the effect of group solution-focused training on couples' marital adjustment. Journal of Psychological Achievements (Educational Sciences and Psychology), 14\&16(1), 51-66. Retrieved from http://www.sid.ir/4..613880103.

Davoodi, Z. (2009). Effectiveness of solution-focused approach in decreasing the tendency to divorce in men and women tending to divorce in the city of Isfahan (Unpublished MA thesis of Family Counseling). Isfahan: University of Isfahan, Faculty of Education and Psychology.

Eisanejad, O., Ahmadi, A., \& E'temadi, A. (2009). Effectiveness of enriching the relationship in improving the quality of couples' marital relationships. Behavioral Sciences, 4(1), 9-16. Retrieved from http://www.noormags.ir/view/fa/articlepage/9167743

Ghamari, M. (2009). Investigating the effectiveness of solution-focused counseling in reducing the different aspects of marital conflicts of dual-career couples. Quarterly Journal of Family Research, 5(19). Retrieved from http://www.SIDir78913881904 215/1/31

Harvey, M. (2009). Couple Therapy. Tehran: Danjeh.

Javanmiri, L., Kimiai, S. A., \& Ghanbri Hashmabadi, B. A. (2012). The study of solution-focused Group counseling in decreasing damage in Teenage Girls. International Journal of Psychological Studies, 1. Retrieved from http://dx.doi.org/1005539/ijps.75n1p105

Javanmiri, L., Kimiaei, A., \& Ghanbri Hashemabadi, B. A. (2012). Investigating the effectiveness of solution-focused group counseling in decreasing depression in young girls (Unpublished MA Thesis). Ferdowsi University of Mashhad, Faculty of Education and Psychology, Mashhad. Retrieved from http://www.um.ac.ir/module-Abstract-viw-pid-8760

Khajeh, A. H., Bahrami, F., Fatehi, M., Abedi, M. R., \& Sajadian, P. (2013). Effectiveness of cognitive-behavioral teaching of joyfulness on the quality of marriage of married men and women. Knowledge \& Research in Applied Psychology, 14(3), 11-21. Retrieved from http://journals.khuisf.ac.ir/jsr-p/b/browse.php?a-id8778 slc 
Kimiaei, S. A., Salehi Fadri, J., \& Azadi, Z. (2011). Comparing the effectiveness of solution-focused and rational-emotional-behavioral couple therapy in reducing marital problems and conflicts of couples applying for divorce (Unpublished MA thesis). Ferdowsi University of Mashhad, Faculty of Educational Sciences.

Mudd, J. E. (2000). Solution-focused therapy and communication Skills Training: An integrated approach to couples therapy.

Nazari, A. M., \& Beirami, M. (2008). Investigating the effect of solution-focused counseling on marital satisfaction in aggression, time spent together, agreement on financial issues and sexual satisfaction in dual-career couples. Quarterly Journal of Psychological Research of University of Tabriz, 3(9).

Nazari, A. M., Navabinejad, S., Kianmanesh, A., \& Sanaee, B. (2004). Investigating and comparing the effect of relationship enrichment program and solution-focused counseling on the marital satisfaction of dual-career couples (Ph.D dissertation). Faculty of Psychology and Educational Sciences, Department of Counseling, Kharazmi University of Tehran. Retrieved from http://www.sid.ir.Archivesofsid

Nocoles, M., \& Schwartz, R. (2010). Family Therapy, Concepts and Methods (2nd ed.). Tehran: Danjeh.

Olia’, N., Fatehizadeh, M., \& Bahrami, F. (2011). How to Enrich a Marriage. Tehran, Danjeh.

Poorchelo, A., Mikaeili, N., \& Narimani, M. (2011). Comparing the effectiveness of cognitive-behavioral stress management and group transactional analysis in improving marital satisfaction and the life quality of women with marital challenges (Unpublished MA thesis). Faculty of Humanities, Department of Psychology, University of Mohaghegh Ardabili, Ardabil. Retrieved from http://www.uma.ac.ir/index.php?site $=984997893 f 151$

Rajabi, G. (2009). Factor structure of the scale of marital satisfaction in married staff of Shahid Chamran University of Ahvaz. Iranian Journal of Psychiatry and Clinical Psychology, 15(4), 351-358. Retrieved from http://www.normags.com

Sanayee, B. (2008). Scale of Measurement of Family and Marriage (2nd ed.). Tehran: Behesht Publication.

Savadeni, M., Shafiabadi, A., \& E’temadi, A. (2010). Comparing the effectiveness of individual and group solution-focused treatment in decreasing family disputes. Journal of Educational Psychology, 5(14), 39-59. Retrieved from http://www.noormags.ir/view/fa/971873

Sehat, N., Sehat, F., Khanjani, S., Mohebi, S., \& Shahsia, M. (2014). Effect of short-term solution-focused approach of couple therapy on marital adjustment in women of the city of Qom. Journal of Health System Research, 10(1).

Stewart, J. W. (2011). A Pilot study of solution-focused Brief Therapeutic intervention of couples Dissertations [electronically on]. Retrieved from http://digital commns.usu.edu/etd/1061

Vahid Vaghef, M., Shfiabadi, A., \& Abdullah, M. (2010). Comparing the effectiveness of two relationship analysis and solution-focused approaches in interpreting the degree of marital satisfaction of couples living in Tehran (MA thesis). Faculty of Educational Sciences, Department of counseling Marvdasht, Islamic Azad University, Marvdasht Branch.

Yousofi, N., Bashlideh, K., E'sanejad, A., E’temadi, A., \& Shirbegi, N. (2011). The relationship between love-making styles and marital quality among married people. Jahad Daneshgahi, Scientific database, 1(1), 21-36. Retrieved from http://fa.journals.sid.ir./view paper.aspx?ID160208

\section{Copyrights}

Copyright for this article is retained by the author(s), with first publication rights granted to the journal.

This is an open-access article distributed under the terms and conditions of the Creative Commons Attribution license (http://creativecommons.org/licenses/by/4.0/). 